Article

\title{
Such a Shame! A Study on Self-Perception of Household Food Waste
}

\author{
Luca Falasconi $^{1}{ }^{1}$, Clara Cicatiello ${ }^{2, *}$, Silvio Franco $^{3}$, Andrea Segrè ${ }^{1}$, Marco Setti ${ }^{1}($ and \\ Matteo Vittuari ${ }^{1}$ (D) \\ 1 Department of Agricultural and Food Sciences, University of Bologna, Viale Fanin 50, 40127 Bologna, Italy; \\ luca.falasconi@unibo.it (L.F.); andrea.segre@unibo.it (A.S.); marco.setti@unibo.it (M.S.); \\ matteo.vittuari@unibo.it (M.V.) \\ 2 Department of Innovation in Biological, Agro-food and Forest Systems, University of Tuscia, Via San \\ Camillo de Lellis snc, 01100 Viterbo, Italy \\ 3 Department of Economy, Engineering, Society and Business, University of Tuscia, Via del Paradiso 47, \\ 01100 Viterbo, Italy; franco@unitus.it \\ * Correspondence: cicatiello@unitus.it; Tel.: +39-761-357-893
}

Received: 2 November 2018; Accepted: 31 December 2018; Published: 8 January 2019

\begin{abstract}
Reducing food waste is globally considered as a key challenge in developing sustainable food systems. Although most food waste is generated at the household level, consumers hardly recognize their responsibility, and the factors underpinning their perception of the quantity of food wasted at home are still unclear. This paper aims to fill this gap by analyzing the results of a large-scale survey conducted in Italy. The perceived quantity of household food waste was measured through a Likert scale and analyzed by means of a logistic regression against a set of predictors, including food waste motivations, perception of the effects of food waste, and sociodemographic variables. As expected, the perceived quantity of food waste declared by respondents was very low. Among the main determinants, food shopping habits and the level of awareness about the reasons why food is wasted played a key role. In contrast, the perception of the environmental effects of food waste seemed to be less important. Differences among subsamples recruited in different areas of Italy were detected, suggesting that further studies, as well as awareness-raising policies, should also consider context-related variables.
\end{abstract}

Keywords: household food waste; awareness; consumer behavior; environmental education; food waste prevention; logistic regression

\section{Introduction}

Food waste is recognized as a global issue, and its reduction is considered to be a crucial element in developing a sustainable food system [1]. According to the Food and Agriculture Organization of the United Nations (FAO) [2], about 1.3 billion tons of food, equivalent to one-third of all the food produced for human consumption, is lost or wasted every year. Such an amount of food waste represents a missed opportunity to achieve global food security as well as to mitigate the use of resources and the resulting environmental impacts [3-11]. Indeed, the impact of food waste on the environment (and on the sustainability of food systems as a whole) has been widely studied, with research confirming that it occurs at all steps of the food supply chain [2,12-20].

In the EU-28, 89 million tons of food is wasted every year, equivalent to 173 kilograms of food waste per person, with $53 \%$ of this food waste being produced at the household level [21]. Several studies conducted in industrialized countries have confirmed that private households are the main producers of food waste in the food chain [22-24]. According to the Waste and Resources 
Action Programme (WRAP) [25], about $60 \%$ of household food waste in the UK is avoidable, i.e., food products that could have been eaten. Despite the high variability in the results of studies aimed at quantifying household food waste [26], the yearly amount of household food waste per capita has been assessed as a quantity between $23 \mathrm{~kg}$ [27-29] and $48 \mathrm{~kg}$ [30] when food waste is directly measured at the households.

In Italy, the yearly amount of food waste is estimated at 6.5 million tons, with $48 \%$ of this waste generated at the household level [31]. The carbon footprint of this food waste represents around 3\% of the total Italian carbon footprint. The water required in the agricultural sector to produce the food that is thus lost is equivalent to 1200 billion liters [20,32].

Recent research on the dynamics underpinning household food waste show it is a complex phenomenon that is influenced by many factors and multiple types of motivational and behavioral patterns [33,34]. Motivations to reduce household food waste include financial reasons and social concerns, i.e., a sense of shame related to throwing food away [35], resulting in the evidence that anticipated regret is a predictor of reducing food waste behavior [36]. WRAP [37] identifies the main determinants of household food waste as the interpretation and use of date labels and food storage habits at home, which are not always consistent with storage guidance reported on the packaging. Subsequent studies have confirmed that consumers' motivation to avoid food waste as well as their capacity to manage food provisioning and food handling influence their food waste behaviors [38-40]. It follows that, to successfully reduce food waste at this step of the food chain, a clear understanding of the drivers influencing consumer perceptions and behaviors regarding food waste is needed.

Food wastage at the household level is related to the individual behavior of consumers as a consequence of inattention or conscious decisions, both in-store and at home, when food is stored, cooked, and consumed $[33,38,41]$. Socioeconomic and demographic household characteristics are also considered a driver of household food waste [41-43], together with dietary habits [44].

As a result of the efforts made by policy makers in promoting awareness campaigns and initiatives against food waste [45], consumers' knowledge about the issue of food waste is increasing. However, there is still little evidence regarding the determinants of consumers' perception of food waste at home [39]. Lyndhurst [46] and Watson and Meah [47] argued that consumers are concerned about food waste because they see it as a waste of money or, only to a general extent, as an ethical drawback $[35,36]$, while the negative effects on the environment seem to have little importance in their perception. Thus, it seems that consumers perceive food waste as a private behavior more than as an environmental behavior [39].

With the aim of contributing to the lively debate on consumers' perception of food waste, this paper explores the behavioral and sociodemographic factors underpinning the amount of household food waste self-declared by 1201 food shoppers interviewed in Italy. The objective of the analysis is twofold: (i) to understand the extent to which consumers perceive their wasteful behavior at home and (ii) to disclose the factors affecting such perceptions. Differently from other studies based on questionnaires [14,48,49], our aim is not to provide a quantification of the food waste generated at home but rather to study the factors that influence the perception of such quantity.

To do so, the paper is structured as follows. The Methodology section reports how the survey was conducted and explains the statistical model used to analyze the data. The results of the model are described in the following section. In Section 4, the results are commented against extant literature, while some more general considerations are reported in the Conclusions.

\section{Methodology}

\subsection{Survey}

A direct survey was conducted in 2014 to analyze consumers' perception toward household food waste. A questionnaire was administered to 1201 food shoppers in the two Italian cities of Bologna and Viterbo, which are located in the northern and central parts of the country and are home to 
387,000 and 67,000 inhabitants, respectively. In terms of wealth, the area of Viterbo is very close to the national average of $€ 19,500$ of yearly revenue per capita, while the area of Bologna is relatively richer with $€ 25,106$ of revenue per capita as measured in 2016 [50]. Respondents were recruited at two hypermarkets belonging to the same chain. Food shoppers were approached after completing their purchases, and the study included only respondents over 18 and under 60 years of age, following the evidence suggested by Waste Watcher [49] that people in their working age are more likely to waste food. Convenience sampling was applied, so recruitment of shoppers did not follow a probabilistic design; rather, the questionnaire was administered to the available shoppers. The sampling method is therefore nonprobabilistic, but as authors from different disciplines [51-53] have suggested, it is well suited for exploratory studies.

As household food waste is predominantly the result of private/hidden behavior [33], we tried to avoid possible bias due to the influence of the interviewer by asking respondents to self-fill the questionnaire. In this way, we intended to give them the privacy needed to freely declare the extent of food waste at their household. The questionnaire was organized in five sections and concerned the following:

1. food purchasing behavior;

2. extent and types of food discarded in the household;

3. evaluation of the motivations, effects, and remedies of food waste;

4. personal food waste choices; and

5. sociodemographic data.

Sections 1 and 5 were made up of closed-ended questions. Sections 2 and 3 required respondents to self-estimate, on a Likert scale ranging from 0 to 10, the quantity of food wasted by their household, the importance of a set of motivations, the perception of effects of food waste, and their opinion on a list of possible strategies against food waste. The Likert scales were anchored at the extremes for better calibration of the answers. In the item concerning the self-estimation of the quantity of household food waste, the value 0 was noted with "nothing", while 10 corresponded to "a lot"; in the other items, where respondents were asked to state the importance of motivations and effect of food waste or the effectiveness of measures against food waste, the wording changed to "not at all" for the value 0 and "very much" for the value 10. Section 4 was intended as a set of items to verify the personal attitude of the respondents with regard to food waste by asking whether they would eat the peel of an apple and a wizened, bruised, or rotten fruit.

Data were cleaned up to delete statistical units with over $15 \%$ missing values. The final database used for the statistical analysis consisted of 1172 observations, out of which 922 were from Bologna and 250 from Viterbo.

\subsection{Statistical Analysis}

The data set was first analyzed with common descriptive statistics to explain the features of the sample and the consistency of the respondents' profile across the two subsamples recruited in Bologna and Viterbo. The two subsamples were then compared with a nonparametric test (Mann-Whitney) for all the 43 variables included in the database. For most variables, the test confirmed no significant differences between the two subsamples. The main exceptions concerned the sociodemographic profile, with the level of education, the number of members in the household, and the income being significantly different with $p$-value $<0.0001$.

A binary logistic regression model was then developed to analyze the factors underpinning respondents' self-perception of household food waste. To do this, two items were combined to construct a binary dependent variable named "declared food waste". Such items requested respondents to estimate, on a 0-10 Likert scale, how often (i) uncooked food and (ii) cooked food were wasted in their households. The corresponding scores were added up, and a new dummy variable was constructed (Figure 1), where scores over 6 (third quartile) were considered "high declared food waste". It should 
be noted that the average scores of both original items were significantly low: 2.30 for uncooked food and 2.05 for cooked food, with 172 respondents (14.7\%) declaring no waste at all. This is consistent with previous evidence that questionnaires are not able to provide reliable evidence in terms of quantity of food waste [26]; rather, they can be successfully used to investigate the root causes of consumers' behavior regarding food waste.

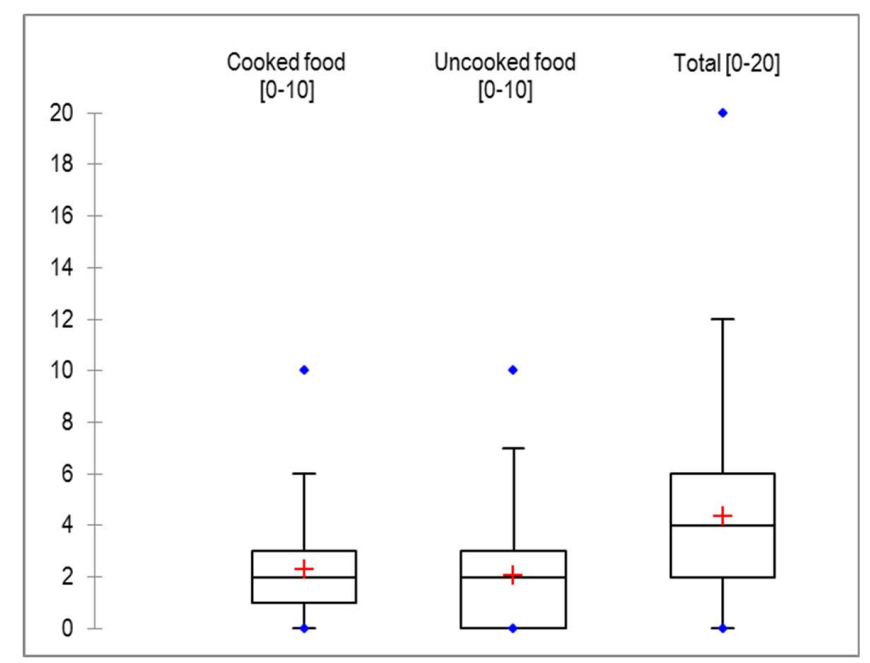

Figure 1. Self-perception of household food waste.

"Declared food waste" was used as a dependent variable in a binary logistic regression, where a set of 23 explanatory variables was considered, including food shopping behavior, motivations to waste, and perception of the effects of food wasting behavior as well as demographic variables (education, size of the household, gender, and age of the respondent). After the first round of elaborations, only the 12 variables with statistically significant parameters were retained and inputted in the final regression model. The final model was set so as to exclude the 62 statistical units (61 from Bologna and 1 from Viterbo) with missing values in the dependent variable or in the factors; therefore, the results of the regression analysis are based on 1110 observations. The parameters of the model allowed to estimate the expected probability of an observation to fall in the "high declared food waste" category according to the values of the independent variables. The logit coefficients reported the expected change in the response variable for a one-unit increase in the predictors according to the log-odds scale, assuming the other variables in the model are held constant.

\section{Results}

\subsection{Descriptive Statistics}

The sample was mostly made up of women (66\%), aged under 40 years $(69 \%)$, and living in small households (62\%). Respondents declared a high level of education, with $46 \%$ holding a university degree, although this case was more frequent in Bologna than in Viterbo. Substantial differences among the subsamples were detected for the income levels as well (Figure 2), with $50 \%$ of the respondents from Viterbo declaring a monthly income of $€ 1500$ or less, while only $25 \%$ of the respondents from Bologna declared the same; in Bologna, the most frequent income class was $€ 2000-3000$. It should be noted, however, that $2.6 \%$ of respondents did not answer this question, which was the reason we did not include this item in the regression model.

Concerning food purchasing habits, most respondents stated they purchase food at supermarkets or hypermarkets, typically once a week. Food shopping seemed to be highly affected by special offers. As respondents self-evaluated their inclination to buy products on offer, the average score was 6.624 on a Likert scale where 0 corresponded to "not influenced at all by offers" and 10 to "highly influenced by offers". Descriptive statistics of the related variables are reported in Tables 1 and 2. 


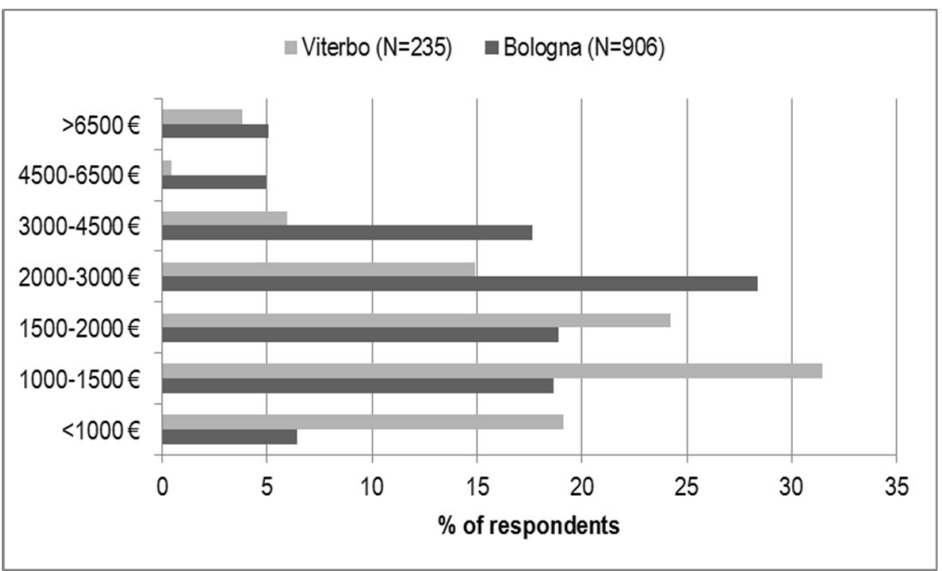

Figure 2. Share of respondents by monthly income of the household $(\mathrm{N}=1141)$.

Table 1. Descriptive statistics of the sample-quantitative variables $(\mathrm{N}=1172)$.

\begin{tabular}{|c|c|c|c|c|}
\hline Quantitative Explanatory Variables & Range Min-Max & Missing Values & Mean & Std. Dev. \\
\hline \multicolumn{5}{|l|}{ Food shopping behavior } \\
\hline Attention to special offers & $0-10$ & 11 & 6.624 & 2.571 \\
\hline \multicolumn{5}{|l|}{ Motivations of food waste } \\
\hline I bought low-quality food & $0-10$ & 9 & 1.933 & 2.799 \\
\hline I bought too much food & $0-10$ & 8 & 2.946 & 2.947 \\
\hline I cooked too much food & $0-10$ & 9 & 2.731 & 2.842 \\
\hline I tried something I did not like & $0-10$ & 7 & 2.318 & 2.677 \\
\hline I bought large packages to save money & $0-10$ & 10 & 2.213 & 2.694 \\
\hline I did not check the expiration date & $0-10$ & 3 & 3.595 & 3.295 \\
\hline I do not reuse leftovers & $0-10$ & 8 & 1.945 & 2.874 \\
\hline \multicolumn{5}{|l|}{ Perception of the effects of food waste } \\
\hline It is a waste of money & $0-10$ & 5 & 6.778 & 3.162 \\
\hline It is a waste of time & $0-10$ & 8 & 3.848 & 3.488 \\
\hline It makes me feeling guilty & $0-10$ & 9 & 5.801 & 3.557 \\
\hline It is a problem for waste management & $0-10$ & 1 & 3.908 & 3.369 \\
\hline It is an economic loss for the society & $0-10$ & 1 & 4.550 & 3.496 \\
\hline It could have been valuable for others & $0-10$ & 1 & 7.237 & 3.226 \\
\hline It is an environmental problem & $0-10$ & 2 & 5.015 & 3.589 \\
\hline
\end{tabular}

Table 2. Descriptive statistics of the sample—categorical variables $(\mathrm{N}=1172)$.

\begin{tabular}{|c|c|c|c|c|}
\hline Categorical Explanatory Variables & Categories & Missing Values & No. Obs. & Frequency \\
\hline \multicolumn{5}{|l|}{ Subsamples } \\
\hline City & $\begin{array}{l}\mathrm{BO}=\text { Bologna } \\
\mathrm{VT}=\text { Viterbo }\end{array}$ & 0 & $\begin{array}{l}922 \\
250\end{array}$ & $\begin{array}{l}78.67 \% \\
21.33 \%\end{array}$ \\
\hline \multicolumn{5}{|l|}{ Food shopping behavior } \\
\hline Frequency of food purchases & $\begin{array}{l}0=\text { less than } 3 \text { times } / \text { week } \\
1=3 \text { times } / \text { week or more }\end{array}$ & 0 & $\begin{array}{l}671 \\
501\end{array}$ & $\begin{array}{l}57.25 \% \\
42.75 \%\end{array}$ \\
\hline \multicolumn{5}{|l|}{ Eating behavior } \\
\hline $\begin{array}{l}\text { Waste of wizened apple } \\
\text { Waste of bruised apple }\end{array}$ & $\begin{array}{l}1=\text { yes } \\
1=\text { yes }\end{array}$ & $\begin{array}{l}38 \\
38\end{array}$ & $\begin{array}{l}232 \\
104\end{array}$ & $\begin{array}{c}20.463 \% \\
9.17 \%\end{array}$ \\
\hline \multicolumn{5}{|l|}{ Sociodemographic variables } \\
\hline Level of education & $\begin{array}{l}0=\text { no degree } \\
1=\text { degree }\end{array}$ & 0 & $\begin{array}{l}630 \\
542\end{array}$ & $\begin{array}{l}53.75 \% \\
46.25 \%\end{array}$ \\
\hline Household size & $\begin{array}{l}0=\text { less than } 3 \text { persons } \\
1=3 \text { persons or more }\end{array}$ & 1 & $\begin{array}{l}728 \\
443\end{array}$ & $\begin{array}{l}62.17 \% \\
37.83 \%\end{array}$ \\
\hline Gender & $\begin{array}{l}0=\text { female } \\
1=\text { male }\end{array}$ & 7 & $\begin{array}{l}769 \\
396\end{array}$ & $\begin{array}{l}66.01 \% \\
33.99 \%\end{array}$ \\
\hline Age & $\begin{array}{l}0=\text { under } 40 \text { years old } \\
1=\text { over } 40 \text { years old }\end{array}$ & 0 & $\begin{array}{l}811 \\
361\end{array}$ & $\begin{array}{l}69.20 \% \\
30.80 \%\end{array}$ \\
\hline
\end{tabular}


As for the questions concerning the extent of food waste at home, the self-evaluation provided, in general, very low scores, both for cooked and uncooked food. Different levels of declared food waste were reported by respondents for different food categories (Figure 3). The highest waste was reported for fruit and vegetables, followed by bread, eggs, and dairy products, i.e., the products with shorter shelf life. However, there was a high heterogeneity among the answers, with many outliers. The average scores were indeed quite low for all the food categories included in the questionnaire.

Respondents were also asked to rate the motivations of food waste in their households. Incorrect management of expiration dates was the motivations that scored the highest, suggesting a lack of attention to the information reported in the labels or a lack of knowledge about the meaning of use-by and best-before dates. Other significant motivations for food waste included over-purchasing and over-cooking.

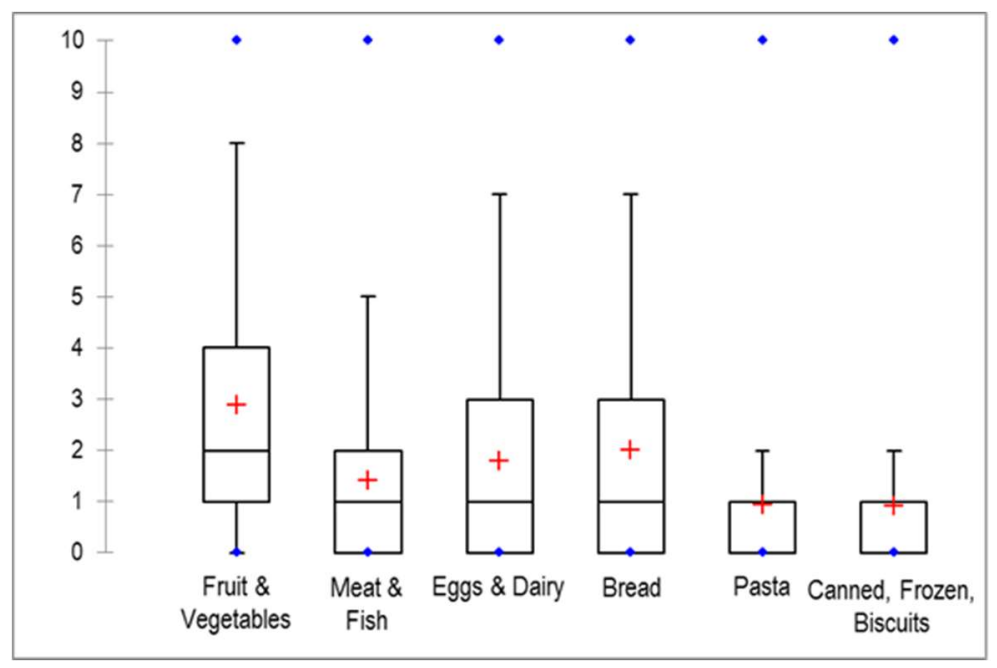

Figure 3. Declared quantity of food wasted by type $(\mathrm{N}=1172)$.

The average and median scores of the items related to respondents' perception of the effects of food waste were rather high in general. The ethical issue linked to food waste ("food that could have been valuable for others") was strongly perceived by respondents as was the economic loss for the household ("it is a waste of money"). A large share of respondents reported that wasting food makes them feel guilty. Compared to items revealing a personal discomfort toward food waste, lower scores were assigned to the effects of food waste concerning the society as a whole.

\subsection{Logistic Regressions}

"Declared food waste" was used as a dependent variable in a binary logistic regression, with the other variables inputted as predictors; $R^{2}$ (Nagelkerke) was 0.273 .

Table 3 reports the parameters of the model. The logit parameters are the log-odds of a general observation to move from the reference category (equal to 0 of the dependent variable, i.e., low food waste declared) to the "high declared food waste" category for a one unit increase in the predictor, while the other variables in the model are held constant. Log-odds are a logarithmic transformation of the odds ratio, i.e., the ratio of the probability of success (moving to the next category of declared food waste) over the probability of failure (staying in the zero waste category) [54]. It follows that, when the probability of moving to the next category for a one unit increase in the explicative is above (below) $50 \%$, the odds ratio is $>1(<1)$, therefore the log-odds is positive (negative). The higher the parameter, the higher is the probability that an observation moves to the "high declared food waste" category.

Among the motivations, "I bought too much food", "I cooked too much food", and "I do not use leftovers" showed a strong influence on the dependent variable, increasing the probability of the observations to declare a high household food waste. The same effect, although with lower log-odds, 
was found for the motivations linked to expiration dates and low quality of the food products. Less influence on declared food waste was found for the variables related to the perception of the effects of food waste. One predictor related to the effects of food waste on the individuals ("it is a waste of money") was found to be significant at $99 \%$ confidence level, with negative log-odds. Therefore, the higher the perception of the effect of food waste on the money available to the household, the lower was the probability to declare high food waste. Two other variables related to the effects of food waste for the society as a whole ("it is a problem for waste management" and "it could have been valuable for others") were found to be significant at $90 \%$ and $95 \%$ confidence levels, respectively, with positive log-odds. As expected, wasting a wizened apple was a behavior that strongly predicted the likelihood of declaring a high food waste (wasting a bruised apple was not significant, and this item was therefore excluded from the final model). Among the demographic variables, the size of the household somewhat predicted the extent of declared food waste, with almost $90 \%$ confidence but a large parameter. In contrast, other demographic factors that had been included in the first round of modeling, such as the level of education, gender, and age of the respondents, were not significant, and they were then excluded from the elaborations. Respondents from Viterbo were found to have a higher probability of declaring high food waste compared to respondents from Bologna. This variable was significant at $99 \%$ confidence and showed large log-odds.

Table 3. Parameters of the binary logistic regression.

\begin{tabular}{|c|c|c|c|c|c|}
\hline Predictors & Parameter & Std. Error & Wald Chi Square & $\operatorname{Pr}>\mathrm{Chi}^{2}$ & Odds Ratio \\
\hline I bought low-quality food & $0.050 *$ & 0.028 & 3.142 & 0.076 & 1.052 \\
\hline I bought too much food & $0.108^{* * *}$ & 0.034 & 9.825 & 0.002 & 1.114 \\
\hline I cooked too much food & $0.111^{* * *}$ & 0.034 & 10.456 & 0.001 & 1.118 \\
\hline I did not check the expiration date & $0.078^{* * *}$ & 0.025 & 9.735 & 0.002 & 1.081 \\
\hline I do not reuse leftovers & $0.113 * * *$ & 0.027 & 17.116 & $<0.0001$ & 1.120 \\
\hline It is a waste of money & $-0.114^{* * *}$ & 0.028 & 16.107 & $<0.0001$ & 0.892 \\
\hline It is a problem in waste management & $0.046^{*}$ & 0.026 & 3.167 & 0.075 & 1.047 \\
\hline It could have been valuable for others & $0.059^{* *}$ & 0.030 & 3.893 & 0.048 & 1.061 \\
\hline City_Bologna & 0.000 & 0.000 & & & \\
\hline City_Viterbo & $0.755^{* * *}$ & 0.188 & 16.188 & $<0.0001$ & 2.127 \\
\hline Frequency of food purchases- 0 & 0.000 & 0.000 & & & \\
\hline Frequency of food purchases-1 & $-0.357^{* *}$ & 0.162 & 4.847 & 0.028 & 0.700 \\
\hline Waste of wizened apple- 0 (no) & 0.000 & 0.000 & & & \\
\hline Waste of wizened apple- -1 (yes) & $0.893^{* * *}$ & 0.181 & 24.360 & $<0.0001$ & 2.442 \\
\hline Household size -0 (up to 3 members) & 0.000 & 0.000 & & & \\
\hline Household size-1 (aver 3 members) & 0.267 & 0.163 & 2.696 & 0.101 & 1.306 \\
\hline
\end{tabular}

\section{Discussion}

On average, respondents declared they wasted a very limited amount of food, and nearly one out of six respondents stated that no food waste wasted by the household. In contrast, literature provides significant evidence that most of the food waste generated along the supply chain occurs at the last stage, i.e., at home $[2,21,23,55,56]$. This confirms that, when consumers are asked to self-assess the extent of food waste at home, they systematically provide underestimated values $[26,57,58]$. However, respondents' perception of the categories of food that are wasted more frequently was in line with previous research $[29,33]$.

Consistent with previous literature, the main motivation identified by respondents for food waste at home was the correct understanding of, and the attention to expiration dates [27,33,59]. Consumers' attention to the effects of food waste was higher when they are personally concerned (feeling guilty, throwing out food that could be valuable to others), as already suggested by Graham Rowe [35].

Looking at the factors influencing the perceived quantity of household food waste, motivations had a key role. Indeed, food waste behavior is commonly believed to be influenced by attitudinal variables and food habits [33]. The results suggested that food shopping routines also matter as buying too much food was a strong predictor of the level of food waste declared. With respect to this issue, 
several authors [41,59] found that making a shopping list may avoid the purchase of unnecessary products, which are more likely to be wasted, thus decreasing the quantity of food discarded at home. In contrast, attention to special offers on food products did not emerge as a driver of the extent of household food waste, which is consistent with previous researches, suggesting that attention to price is not correlated with over-purchasing [60]. The literature suggests that greater awareness of the environmental issues related to food waste, together with a cultural shift in the perception of food waste value, may result in a decrease in household food waste [56]. However, scarce evidence was found in this study to this effect. Results showed that household food waste was slightly influenced by respondents' perception of the effects on waste management issues but, in general, the impact of food waste on individual assets (money available to the household) was more significant in predicting the amount of food waste declared. Similarly, the only significant driver linked to ethical issues was the feeling of wasting food that could have been valuable for others.

Regarding the social and demographic variables, our findings suggest they can influence the amount of food waste declared by respondents to a certain extent. In the literature, youths are reported to waste more than elderly people [45,49], but no evidence was found in this study regarding this. However, it should be noted that our sample was limited to people under 60 years old, while literature suggests that people aged 65 or over waste significantly less food than the rest of the population [27]. Similarly, we did not find education as a significant predictor of the level of household food waste, and the role of income was not tested due to high inconsistency of data across the two subsamples. Some studies have found evidence of a higher waste in households with higher education and higher income $[27,45,61]$. Additional indications emerged from a comparison of the two subsamples. A higher frequency of household food waste was found among the respondents recruited in the city of Viterbo (31.60\% of respondents declared high food waste compared to $21.58 \%$ in Bologna). To analyze more deeply such differences, the logistic regression model was run again with the same set of explanatory variables, separately for the two subsamples (detailed results are reported in Appendix A). Although the explanatory power of the model decreased, especially in the analysis on the subsample from Viterbo due to its relatively small size, a comparison among the respective results revealed some interesting insights. First, purchasing low quality food was no longer a significant parameter in the subsample from Bologna (Table A1), while it was so for the respondents recruited in Viterbo (Table A2). This may suggest that food shopping habits vary with the socioeconomic context, thus affecting the amount of food wasted at households in different ways. Second, the perception of food waste as a "waste of money" had, in Bologna, a much lower impact on the amount of food waste declared by respondents compared to the other subsample. This may be due to the different economic conditions of the people living in the two study areas, which is likely to affect their perception of food waste as an economic issue, although the influence of household income on the amount of food waste is still not fully understood [35]. Moreover, when the subsample from Bologna was studied alone, the feeling of throwing out food that could have been valuable to others was no longer significant as a predictor of the amount of declared food waste, while it was so in the subsample from Viterbo. Finally, the reuse of leftovers and the frequency of food shopping were both predictors of the amount of household food waste declared in the area of Bologna, while they were not so in the subsample from Viterbo.

These evidences suggest that context variables have a role in influencing the food waste behavior of consumers at home as a consequence of different food shopping habits and sensitivity to the issue of food waste in areas with different socioeconomic features. This is consistent with the conceptual framework proposed in the literature (References [38,42,45], among others), where consumer behavior toward household food waste is conceived as dependent on two sets of variables, i.e., the individual characteristics of the respondents and the features of the area where they live. Among the several context variables that may influence household food waste, cultural, governmental, technological, economic, and production variables can be mentioned [33].

In the interpretation of the results, some limitations of the study have to be considered. It should be recalled that the study is based on respondents' perception of the quantity of household food 
waste, which is likely to be underestimated [26]. Therefore, the dependent variable used in the model cannot be considered a reliable proxy for the actual quantity of food waste produced by respondents' households; rather, it can be used as a proxy for consumer awareness of their wasteful behavior at home. In this light, it appears clearer why respondents' awareness of motivations underpinning food waste at home emerges as a strong predictor of the quantity of food waste declared; consumers who are more aware of why they waste food at home may be likely to declare more food waste as a consequence of their higher concern about the issue. Another limitation concerns the discrepancy in the number of respondents recruited in the two study areas, which does not allow drawing conclusive evidence with respect to the role of the context in determining consumer awareness and perception of the food waste issue.

\section{Conclusions}

This study was aimed at exploring the factors underpinning consumer perception of household food waste at home by analyzing the results of a large survey conducted in Italy in which the self-perception of the quantity of household food waste was investigated.

Results showed that food habits were very important to determine the extent of food waste declared. In particular, purchasing and cooking too much food were both related to a higher food waste declared, especially in the subsample from the area of Bologna, thus suggesting that better planning of food purchases could have a role in decreasing food waste at home.

Other drivers concerned the perception of the effects of food waste as we found an association between the perception of wasting money and the tendency to waste less food at home. Environmental concerns, as already highlighted by Lyndhurst [46] and Watson and Meah [47], did not directly influence the generation of household food waste. This suggests that environmental issues are considered to a lesser extent in food decisions, probably because consumers are less likely to connect them to their daily behavior [59]. This reminds us of the need for a stronger effort in designing awareness-raising policies tackling the macro effects of food waste, which are often too complex to be directly perceived by households. In our study, the perception of the effects of food waste showed a high variability within the sample, suggesting that, as far as food choices are concerned, individual and social aspects should be considered together as they interrelate in shaping the food (waste) behavior of people.

With respect to the role of context variables in the generation of food waste at home, we found that declared food waste was higher in the subsample from the area of Viterbo, where the household income and the level of education are lower. Indeed, when the model was run separately for this subsample, results showed meaningful changes. This suggests that the local socioeconomic conditions shape individual choices as well as the awareness about food waste as an issue.

As a recap of the results of this study, it should be recalled once again that respondents were asked to self-assess the extent of food waste at their households, which is likely to be underestimated as a consequence of the personal discomfort they feel in relation to food waste. However, it was not our aim to assess the extent of household food waste; rather, we explored the main factors underpinning respondents' perception (and awareness) of the issue. In studying this issue, we reported many differences among the respondents recruited in different geographical areas, suggesting that further research on household food waste could benefit from a comparison under different socioeconomic contexts. Such comparative effort could help design more effective policies to increase consumer awareness toward food waste.

Author Contributions: L.F., M.S., M.V., and A.S. conceived and designed the experiments; C.C. and S.F. performed the statistical elaborations. In writing the paper, L.F. and M.V. wrote the Introduction; C.C. wrote the Methodology; L.F. and M.S. wrote the Results; C.C. and M.V. wrote the Discussion, S.F. wrote the Conclusions.

Funding: This research received no external funding. 
Acknowledgments: The Authors wish to thank the students that helped in the administration of the survey: Erika Cassanelli, Matteo Garutti, Eduardo Alfredo Chegai. We are thankful to the participants and the reviewers of the 52nd SIDEA Conference, where an early version of this manuscript was discussed, for their valuable inputs and comments.

Conflicts of Interest: The authors declare no conflict of interest.

\section{Appendix A}

Table A1. Parameters of the binary logistic regression conducted on the subsample from Bologna.

\begin{tabular}{|c|c|c|c|c|c|}
\hline Predictors & Parameter & Std. Error & Wald Chi Square & $\mathrm{Pr}>\mathrm{Chi}^{2}$ & Odds Ratio \\
\hline I bought low-quality food & 0.023 & 0.032 & 0.496 & 0.481 & 1.023 \\
\hline I bought too much food & $0.139 * * *$ & 0.040 & 12.221 & 0.000 & 1.149 \\
\hline I cooked too much food & $0.121 * * *$ & 0.039 & 9.566 & 0.002 & 1.129 \\
\hline I did not check the expiration date & 0.054 * & 0.029 & 3.334 & 0.068 & 1.055 \\
\hline I do not reuse leftovers & $0.140 * * *$ & 0.032 & 18.550 & $<0.0001$ & 1.150 \\
\hline It is a waste of money & $-0.085^{* *}$ & 0.035 & 5.889 & 0.015 & 0.918 \\
\hline It is a problem in waste management & $0.078 * *$ & 0.031 & 6.221 & 0.013 & 1.081 \\
\hline It could have been valuable for others & 0.028 & 0.036 & 0.605 & 0.437 & 1.028 \\
\hline Frequency of food purchases -0 & 0.000 & 0.000 & & & \\
\hline Frequency of food purchases-1 & $-0.431 * *$ & 0.194 & 4.961 & 0.026 & 0.650 \\
\hline Waste of wizened apple- -0 (no) & 0.000 & 0.000 & & & \\
\hline Waste of wizened apple—1 (yes) & $1.129^{* * *}$ & 0.209 & 29.105 & $<0.0001$ & 3.094 \\
\hline Household size -0 (up to 3 members) & 0.000 & 0.000 & & & \\
\hline Household size-1 (aver 3 members) & 0.270 & 0.194 & 1.928 & 0.165 & 1.310 \\
\hline
\end{tabular}

Table A2. Parameters of the binary logistic regression conducted on the subsample from Viterbo.

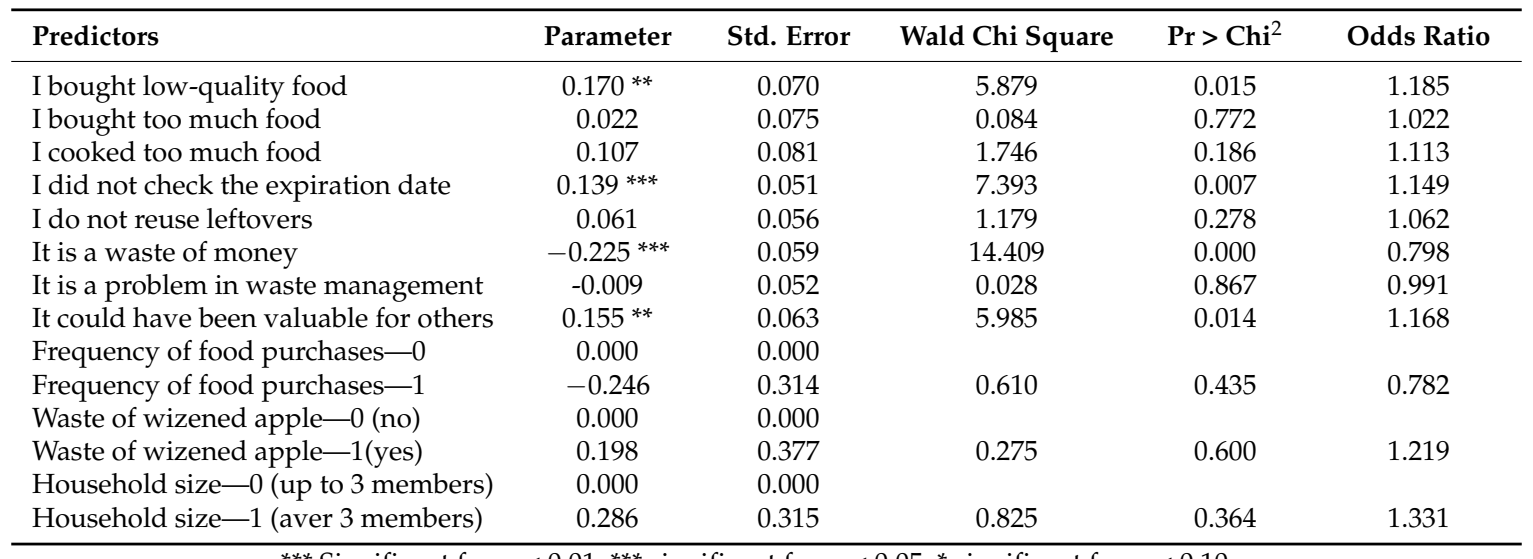

*** Significant for $\alpha<0.01 ; * * *$ significant for $\alpha<0.05 ; *$ significant for $\alpha<0.10$.

\section{References}

1. UN. Transforming Our World: The 2030 Agenda for Sustainable Development. 2015. Available online: https:// sustainabledevelopment.un.org/post2015/transformingourworld/publication (accessed on 24 September 2018).

2. FAO. Global Food Waste and Food Losses. 2011. Available online: http://www.fao.org/docrep/014/ mb060e/mb060e.pdf (accessed on 24 September 2018).

3. Carlsson-Kanyama, A. Climate change and dietary choices-How can emissions of greenhouse gases from food consumption be reduced? Food Policy 1998, 23, 277-293. [CrossRef]

4. Foster, C.; Green, K.; Bleda, M.; Dewick, P.; Evans, B.; Flynn, A.; Mylan, J. Environmental Impacts of Food Production and Consumption: A Report to the Department for Environment, Food and Rural Affairs; Manchester Business School, Defra: London, UK, 2006.

5. Williams, A.G.; Audsley, E.; Sandars, D.L. Determining the Environmental Burdens and Resource Use in the Production of Agricultural and Horticultural Commodities; Main Report; Defra Research Project IS0205; Cranfield University and Defra: Bedford, UK, 2006. 
6. Huppes, G.; de Koning, A.; Suh, S.; Heijungs, R.; van Oers, L.; Nielsen, P.; Guinée, J.B. Environmental impacts of consumption in the European Union: High-resolution input-output tables with detailed environmental extensions. J. Ind. Ecol. 2008, 10, 129-146. [CrossRef]

7. Pimentel, D.; Pimentel, M.H. Food, Energy and Society, 3rd ed.; CRC Press, Taylor and Francis Group: Boca Raton, FL, USA, 2008.

8. Weber, C.L.; Matthews, H.S. Food-miles and the relative climate impacts of food choices in the United States. Environ. Sci. Technol. 2008, 42,3508-3513. [CrossRef] [PubMed]

9. Khan, S.; Hanjra, M.A. Footprints of water and energy inputs in food production-Global perspectives. Food Policy 2009, 34, 130-140. [CrossRef]

10. Notarnicola, B.; Tassielli, G.; Renzulli, P.A.; Castellani, V.; Sala, S. Environmental impacts of food consumption in Europe. J. Clean. Prod. 2017, 140, 753-765. [CrossRef]

11. Sala, S.; Anton, A.; McLaren, S.J.; Notarnicola, B.; Saouter, E.; Sonesson, U. In quest of reducing the environmental impacts of food production and consumption. J. Clean. Prod. 2017, 140, 387-398. [CrossRef]

12. Cuéllar, A.D.; Webber, M.E. Wasted food, wasted energy: The embedded energy in food waste in the United States. Environ. Sci. Technol. 2010, 44, 6464-6469.

13. Kummu, M.; de Moel, H.; Porkka, M.; Siebert, S.; Varis, O.; Ward, P.J. Lost food, wasted resources: Global food supply chain losses and their impacts on freshwater, cropland, and fertilizer use. Sci. Total Environ. 2012, 438, 477-489. [CrossRef]

14. Abeliotis, K.; Lasaridi, K.; Costarelli, V.; Chroni, C. The implications of food waste generation on climate change: The case of Greece. Sustain. Prod. Consum. 2015, 3, 8-14. [CrossRef]

15. Scherhaufer, S.; Lebersorger, S.; Pertl, A.; Obersteiner, G.; Schneider, F.; Falasconi, L.; De Menna, F.; Vittuari, M.; Hartikainen, H.; Katajajuuri, J.M.; et al. Criteria for and Baseline Assessment of Environmental and Socio-Economic Impacts of Food Waste; FUSIONS Project, BOKU University of Natural Resources and Life Sciences, Institute of Waste Management: Wien, Austria, 2015; ISBN 978-3-900932-32-9.

16. Song, G.; Li, M.; Semakula, H.M.; Zhang, S. Food consumption and waste and the embedded carbon, water and ecological footprints of households in China. Sci. Total Environ. 2015, 529, 191-197. [CrossRef] [PubMed]

17. De Laurentiis, V.; Hunt, D.V.; Rogers, C.D. Overcoming Food Security Challenges within an Energy/Water/Food Nexus (EWFN) Approach. Sustainability 2016, 8, 95. [CrossRef]

18. Vittuari, M.; De Menna, F.; Pagani, M. The Hidden Burden of Food Waste: The Double Energy Waste in Italy. Energies 2016, 9, 660. [CrossRef]

19. Brancoli, P.; Rousta, K.; Bolton, K. Life cycle assessment of supermarket food waste. Resour. Conserv. Recycl. 2017, 118, 39-46. [CrossRef]

20. Cicatiello, C.; Franco, S.; Pancino, B.; Blasi, E. The value of food waste: An exploratory study on retailing. J. Retail. Consum. Serv. 2016, 30, 96-104. [CrossRef]

21. Stenmarck, A.; Jensen, C.; Quested, T.; Moates, G. Estimates of European Food Waste Levels; Publication of the FUSIONS Project, European Commission (FP7), Coordination and Support Action-CSA: Stockholm, Sweden, 2016.

22. Food Waste: Causes, Impacts and Proposals. Barilla Center for Food \& Nutrition. 2012. Available online: https://www.barillacfn.com/en/publications/food-waste-causes-impacts-and-proposals (accessed on 21 September 2018).

23. Gunders, D. Wasted: How America is Losing up to 40 percent of its Food from Farm to Fork to Landfill; Natural Resources Defense Council Issue Paper; Natural Resources Defense Council: New York, NY, USA, 2012.

24. Monier, V.; Mudgal, S.; Escalon, V.; O'Connor, C.; Gibon, T.; Anderson, G.; Montoux, H.; Reisinger, H.; Dolley, P.; Ogilvie, S.; et al. Preparatory Study on Food Waste Across EU 27; European Commission: Paris, France, 2011.

25. WRAP. Household Food Waste in the UK. Report 2015. Project Code: CSC107-GEN. 2017. Available online: www.wrap.org.uk (accessed on 24 September 2018).

26. Cicatiello, C.; Giordano, C. Measuring Household Food Waste at National Level: A Systematic Review on Methods and Results. CAB Rev. 2018, 13,1-8. [CrossRef]

27. Koivupuro, H.K.; Hartikainen, H.; Silvennoinen, K.; Katajajuuri, J.M.; Heikintalo, N.; Reinikainen, A.; Jalkanen, L. Influence of socio-demographical, behavioural and attitudinal factors on the amount of avoidable food waste generated in Finnish households. Int. J. Consum. Stud. 2012, 36, 183-191. [CrossRef] 
28. Silvennoinen, K.; Katajajuuri, J.M.; Hartikainen, H.; Heikkilä, L.; Reinikainen, A. Food waste volume and composition in Finnish households. Br. Food J. 2014, 116, 1058-1068. [CrossRef]

29. Katajajuuri, J.M.; Silvennoinen, K.; Hartikainen, H.; Heikkilä, L.; Reinikainen, A. Food waste in the Finnish food chain. J. Clean. Prod. 2014, 73, 322-329. [CrossRef]

30. Edjabou, M.E.; Jensen, M.B.; Götze, R.; Pivnenko, K.; Petersen, C.; Scheutz, C.; Astrup, T.F. Municipal solid waste composition: Sampling methodology, statistical analyses, and case study evaluation. Waste Manag. 2015, 36, 12-23. [CrossRef]

31. Segrè, A.; Falasconi, L. Il Libro Nero Dello Spreco in Italia: Il Cibo; EdizioneAmbiente: Milano, Italy, 2010.

32. Segrè, A.; Falasconi, L. Il Libro Blu Dello spreco in Italia: L'acqua; EdizioneAmbiente: Milano, Italy, 2011.

33. Quested, T.E.; Marsh, E.; Stunell, D.; Parry, A.D. Spaghetti soup: The complex world of food waste behaviours. Resour. Conserv. Recycl. 2013, 79, 43-51. [CrossRef]

34. Setti, M.; Banchelli, F.; Segré, A.; Falasconi, L.; Vittuari, M. Consumption food cycle and household waste. When behaviors matter. J. Clean. Prod. 2018, 185, 694-706. [CrossRef]

35. Graham-Rowe, E.; Jessop, D.C.; Sparks, P. Identifying motivations and barriers to minimising household food waste. Resour. Conserv. Recycl. 2014, 84, 15-23. [CrossRef]

36. Graham-Rowe, E.; Jessop, D.C.; Sparks, P. Predicting household food waste reduction using an extended theory of planned behaviour. Resour. Conserv. Recycl. 2015, 101, 194-202. [CrossRef]

37. WRAP, Consumer Insight: Date Labels and Storage Guidance (Banbury, UK). 2011. Available online: http: / / www.wrap.org.uk/sites / files/wrap/Technical\%20report\%20dates.pdf (accessed on 24 September 2018).

38. Aschemann-Witzel, J.; de Hooge, I.; Amani, P.; Bech-Larsen, T.; Oostindjer, M. Consumer-related food waste: Causes and potential for action. Sustainability 2015, 7, 6457-6477. [CrossRef]

39. Stancu, V.; Haugaard, P.; Lähteenmäki, L. Determinants of consumer food waste behaviour: Two routes to food waste. Appetite 2016, 96, 7-17. [CrossRef]

40. Canali, M.; Amani, P.; Aramyan, L.; Gheoldus, M.; Moates, G.; Östergren, K.; Silvennoinen, K.; Waldron, K.; Vittuari, M. Food waste drivers in Europe, from identification to possible interventions. Sustainability 2017, 9 , 37. [CrossRef]

41. Stefan, V.; Van Herpen, E.; Tudoran, A.A.; Lähteenmäki, L. Avoiding food waste by Romanian consumers: The importance of planning and shopping routines. Food Qual. Prefer. 2013, 28, 375-381. [CrossRef]

42. Evans, D. Blaming the consumer-Once again: The social and material contexts of everyday food waste practices in some English households. Crit. Public Health 2011, 21, 429-540. [CrossRef]

43. Evans, D. Beyond the throwaway society: Ordinary domestic practice and a sociological approach to household food waste. Sociology 2012, 46, 41-56. [CrossRef]

44. Franco, S.; Cicatiello, C. Food waste due to over-nutrition in the Italians' dietary habits. Rivista di Studi Sulla Sostenibilit 2018, 1, 159-180. [CrossRef]

45. Secondi, L.; Principato, L.; Laureti, T. Household food waste behaviour in EU-27 countries: A multilevel analysis. Food Policy 2015, 56, 25-40. [CrossRef]

46. Brook Lyndhurst. Food Behaviour Consumer Researched Findings from the Quantitative Survey. 2007. (Briefing Paper UK: WRAP). Available online: http:/ / www.wrap.org.uk/sites/files/wrap/Food\% 20behaviour\%20consumer\%20research\%20quantitative\%20jun\%202007.pdf (accessed on 24 September 2018).

47. Watson, M.; Meah, A. Food, waste and safety: Negotiating conflicting social anxieties into the practices of domestic provisioning. Sociol. Rev. 2013, 60, 102-120. [CrossRef]

48. Visschers, V.H.; Wickli, N.; Siegrist, M. Sorting out food waste behaviour: A survey on the motivators and barriers of self-reported amounts of food waste in households. J. Environ. Psychol. 2016, 45, 66-78. [CrossRef]

49. Waste Watcher. Osservatorio Sugli Sprechi Alimentari Delle Famiglie Italiane, Rapporto 2013. Available online: http:/ / www.progettareineuropa.com/wp-content/uploads/2016/07/Sprechi-alimentari-in-Italia. pdf (accessed on 24 September 2018).

50. Website of the Italian Ministry of Economy and Finance. Available online: www.finanze.gov.it (accessed on 24 September 2018).

51. Hultsch, D.F.; MacDonald, S.W.S.; Hunter, M.A.; Maitland, S.B.; Dixon, R.A. Sampling and generalisability in developmental research: Comparison of random and convenience samples of older adults. Int. J. Behav. Dev. 2002, 26, 345-359. [CrossRef] 
52. Guerrero, L.; Claret, A.; Verbeke, W.; Enderli, G.; Zakowska-Biemans, S.; Vanhonacker, F.; Issanchou, S.; Sajdakowska, M.; Signe Granli, B.; Scalvedi, L.; et al. Perception of traditional food products in six European regions using free word association. Food Qual. Preference 2010, 21, 225-233. [CrossRef]

53. Farrokhi, F.; Mahmoudi-Hamidabad, A. Rethinking convenience sampling: Defining quality criteria. Theory Pract. Lang. Stud. 2012, 2, 784-792.

54. Hosmer, D.W., Jr.; Lemeshow, S.; Sturdivant, R.X. Applied Logistic Regression; John Wiley \& Sons: Hoboken, NJ, USA, 2013; Volume 398.

55. Griffin, M.; Sobal, J.; Lyson, T.A. An analysis of a community food waste stream. Agric. Hum. Values 2009, 26, 67-81. [CrossRef]

56. Parfitt, J.; Barthel, M.; Macnaughton, S. Food waste within food supply chains: Quantification and potential for change to 2050. Philos. Trans. R. Soc. Lond. B Biol. Sci. 2010, 365, 3065-3081. [CrossRef]

57. Priefer, C.; Jörissen, J.; Klaus-Rainer Bräutigam, K.R. ; Technology Options for Feeding 10 Billion People Options for Cutting Food Waste; European Union: Brussels, Belgium, 2013.

58. Møller, H.; Hanssen, O.J.; Gustavsson, J.; Östergren, K.; Stenmarck, Å.; Dekhtyar, P. Report on Review of (Food) Waste Reporting Methodology and Practice; FUSIONS Project; Østfoldforskning: Kråkerøy, Norway, 2014; ISBN 82-7520-713-4 978-82-7520-713-3.

59. Principato, L.; Secondi, L.; Pratesi, C.A. Reducing food waste: An investigation on the behaviour of Italian youths. Br. Food J. 2015, 117, 731-748. [CrossRef]

60. Aschemann-Witzel, J.; Jensen, J.H.; Jensen, M.H.; Kulikovskaja, V. Consumer behaviour towards price-reduced suboptimal foods in the supermarket and the relation to food waste in households. Appetite 2017, 116, 246-258. [CrossRef]

61. Setti, M.; Falasconi, L.; Segrè, A.; Cusano, I.; Vittuari, M. Italian consumers' income and food waste behaviour. Br. Food J. 2016, 118, 1731-1746. [CrossRef]

(C) 2019 by the authors. Licensee MDPI, Basel, Switzerland. This article is an open access article distributed under the terms and conditions of the Creative Commons Attribution (CC BY) license (http:/ / creativecommons.org/licenses/by/4.0/). 